\title{
Some $\beta$-Aminoketone Derivatives as Corrosion Inhibitors for Nickel in Hydrochloric Acid Solution
}

\author{
G.Y. Elewady, ${ }^{*}$ A.H. El-Askalany and A.F. Molouk \\ Chemistry Department, Faculty of Science, Mansoura University, Mansoura, Egypt
}

Received 7 April 2008; accepted 18 September 2008

\begin{abstract}
The use of some $\beta$-aminoketone derivatives as corrosion inhibitors for nickel in $2 \mathrm{M}$ acid chloride solution was investigated by gravimetric and galvanostatic polarization techniques. It was found that the investigated compounds behave as inhibitors for nickel dissolution and their inhibition efficiencies increase by the addition of iodide ions. Also, the adsorption isotherms were studied and it was found to follow the Frumkin's adsorption isotherm. By increasing the temperature of the corrosive medium containing different concentrations of the tested inhibitors, the corrosion rate of nickel increases, indicating that these inhibitors are physically adsorbed on the metal surface. Finally, some quantum chemical quantities such as HOMO, LUMO and dipole moment of the inhibitors were calculated and correlated with the rate of corrosion.
\end{abstract}

Keywords: $\beta$-aminoketone derivatives, corrosion inhibition, $\mathrm{HCl}$, nickel, quantum chemical calculations.

\section{Introduction}

Nickel is one of the most important metals and is used in a large number of applications. Pure nickel has a good corrosion resistance. When nickel is present with other metals even in small quantities as alloy, the performance corrosion increases. The corrosion resistance of nickel is due to the formation of a passive film on its surface upon exposure to the corrosive media. Many works were conducted to study the passivation of nickel in acidic solutions [1-5]. However, the obtained results showed that nickel establishes a kind of passivity in acidic solutions in which the corrosion current, in the passive potential range, is somewhat higher than those recorded by other passive metals. Due to the use of nickel in contact with acidic solutions, its corrosion rate must be controlled. One

\footnotetext{
* Corresponding author. E-mail address: ghadaelewady@yahoo.com
} 
of the useful methods of controlling the corrosion process is the addition of inhibitors. Several researches were found in the literature about the use of inhibitors for nickel dissolution in acidic solution [6-14]. The aim of this paper is to investigate the effect of three $\beta$-aminoketone derivatives as inhibitors for corrosion of nickel in hydrochloric acid solution, to throw some light on the mechanism of corrosion and to calculate some quantum quantities.

\section{Experimental}

The chemical composition of nickel sheets and wire (BDH grade) was as follows:

\begin{tabular}{|c|c|c|c|c|c|c|c|c|}
\hline Element & $\mathrm{Al}$ & $\mathrm{Co}$ & $\mathrm{Cu}$ & $\mathrm{Fe}$ & $\mathrm{Mn}$ & $\mathrm{Mg}$ & $\mathrm{Ti}$ & $\mathrm{Ni}$ \\
\hline Weight $\%$ & 0.05 & 0.005 & 0.005 & 0.05 & 0.005 & 0.005 & 0.005 & 99.875 \\
\hline
\end{tabular}

BDH grade hydrochloric acid was used for the preparation of the corrosive media. The name and the molecular structure of the three used $\beta$-aminoketone derivatives are as shown below:<smiles>CN(CCC(=O)c1cccs1)CCC(=O)c1cccs1</smiles>

(I) N, N-bis[1-(2-theinyl)-1-propanon-3-yl]methylamine hydrochloride<smiles>O=C(CCN1CCN(CCC(=O)c2ccccc2)CC1)c1ccccc1</smiles>

(II) $\mathrm{N}, \mathrm{N}$-bis( $\beta$-benzoylethyl) piperazine dihydrochloride<smiles>CN(CCC(=O)c1ccccc1)CCC(=O)c1ccccc1</smiles>

(III) 3-piperidin-1-yl-1-thien-2-yl propan-1-one hydrochloride

These compounds were prepared according to reported methods [15-18]. These compounds were subjected to recrystallisation using ethanol and identified by elemental analysis and IR spectra. 
Weight loss measurements were carried out by using sheets of nickel with dimensions of $20 \times 20 \times 2 \mathrm{~mm}$. The samples were first polished with different grades of emery papers to have a smooth surface, rinsed with absolute ethanol and bidistilled water, respectively. Then dried, weighed and immersed in the corrosive medium with and without different concentrations of the inhibitors. After specified periods, the nickel sheets were taken out, rinsed with bidistilled water, dried and weighed. The inhibition efficiency (\%IE) and the degree of surface coverage $(\theta)$ are calculated by the following equations:

$$
\begin{gathered}
\% \mathrm{IE}=\left[\frac{\Delta \mathrm{w}-\Delta \mathrm{w}_{\mathrm{i}}}{\Delta \mathrm{w}}\right] \times 100 \\
\theta=\frac{\Delta \mathrm{w}-\Delta \mathrm{w}_{\mathrm{i}}}{\Delta \mathrm{w}_{\mathrm{i}}}
\end{gathered}
$$

where $\Delta \mathrm{w}$ and $\Delta \mathrm{w}_{\mathrm{i}}$ are the weight losses in absence and presence of the inhibitor, respectively.

The galvanostatic polarization curves were measured using a three compartments pyrex glass cell. The counter electrode was a Pt sheet and a saturated calomel electrode (SCE) was used as a reference electrode. For the working electrode, the nickel wire was polished and cleaned in a similar way of nickel sheets used in gravimetric measurements. The wire was of $1 \mathrm{~cm}$ long and $1.25 \mathrm{~mm}$ diameter sealed to a glass tube with a suitable adhesive. The electrochemical cell was kept at constant temperature $\left(30 \pm 0.1{ }^{\circ} \mathrm{C}\right)$ using an ultra thermostat. From galvanostatic polarization data the percentage inhibition efficiency (\% IE) and degree of surface coverage $(\theta)$ were calculated from the following equations

$$
\begin{gathered}
\% \text { IE }=\left[\frac{\mathrm{i}_{\text {free }}-\mathrm{i}_{\text {inh. }}}{\mathrm{i}_{\text {free }}}\right] \times 100 \\
\theta=\frac{\mathrm{i}_{\text {free }}-\mathrm{i}_{\text {inh. }}}{\mathrm{i}_{\text {free }}}
\end{gathered}
$$

where $i_{\text {free }}$ and $i_{\text {inh. }}$ are the corrosion current densities in absence and presence of inhibitor, respectively.

\section{Results and discussion Weight loss measurements}

The calculated values of inhibition efficiency (\% IE) at $30{ }^{\circ} \mathrm{C}$ from the losses of weight of nickel sheets after immersion in solutions of $2.0 \mathrm{M} \mathrm{HCl}$ containing different concentrations of the investigated compounds are given in Table 1. 
Table 1. Variation of percentage inhibition (\%IE) of $\beta$-aminoketones with their concentrations as calculated from gravimetric measurements after $240 \mathrm{~min}$ immersion at $30{ }^{\circ} \mathrm{C}$.

\begin{tabular}{|c|c|c|c|}
\hline Concentration & \multicolumn{3}{|c|}{ \% Inhibition efficiency } \\
\cline { 2 - 4 } $\mathrm{M}$ & $\mathrm{I}$ & $\mathrm{II}$ & $\mathrm{III}$ \\
\hline $1.0 \times 10^{-5}$ & 39.30 & 39.00 & 30.59 \\
$5.0 \times 10^{-5}$ & 47.52 & 47.03 & 35.04 \\
$1.0 \times 10^{-4}$ & 56.36 & 56.13 & 42.65 \\
$1.5 \times 10^{-4}$ & 58.82 & 58.40 & 50.00 \\
$2.0 \times 10^{-4}$ & 60.30 & 59.30 & 51.13 \\
$2.5 \times 10^{-4}$ & 63.00 & 61.81 & 52.23 \\
\hline
\end{tabular}

From this table it is clear that the inhibition efficiency increases with increasing the concentration of these compounds and the order of the inhibition efficiencies is I > II > III. This behavior indicates that the $\beta$-aminoketone compounds act as inhibitors for nickel corrosion in hydrochloric acid solution. The inhibitive action of the used compounds could be attributed to the adsorption of their molecules on nickel surface, forming a barrier between the metal surface and the corrosive environment.

\section{Synergistic effect}

It was found that the presence of anions like iodide ion in the corrosive solution enhances the inhibitive action of several nitrogen organic compounds in acid solutions $[19,20]$. So, the effect of addition of $1 \times 10^{-4} \mathrm{M} \mathrm{KI}$ in the corrosive medium in presence of different concentrations of the used inhibitors, using gravimetric technique, was studied. The presence of KI increases the inhibition efficiency of the inhibitors, as shown in Fig. 1 (for compound III as an example) and Table 2. This behavior is due to the synergistic effects, which can be interpreted according to Schmitt and Bedbur [21], who proposed two types of joint adsorption, namely competitive and cooperative.

The synergistic inhibition effect was evaluated using $S_{\theta}$ parameter. Aramaki and Hackerman [22] calculated the synergism parameter $S_{\theta}$ by the following equation:

$$
\mathrm{S}_{\theta}=1-\theta_{1+2} / 1-\theta-{ }_{1+2}
$$

where: $\theta_{1+2}=\left(\theta_{1}+\theta_{2}\right)-\left(\theta_{1} \theta_{2}\right), \theta_{1}=$ surface coverage by anion, $\theta_{2}=$ surface coverage by cations, and $\theta^{-}{ }_{1+2}=$ measured surface coverage by both anion and cations.

Table 3 reports $S_{\theta}$ for the three inhibitors. As can be seen from this table, the $S_{\theta}$ values are nearly equal to unity, suggesting that the enhanced inhibition efficiency caused by the addition of iodide ion to the tested compounds is mainly due to the synergistic effect, since the $S_{\theta}$ values are independent of the concentration of additives; so, it can be assumed that there is a constant contribution of the adsorbed inhibitor as cation. It can be concluded that the 
inhibitors are preferentially adsorbed in a protonated form by columbic attraction on the metal surface where the anion is already chemisorbed and suppresses the corrosion rate by the stabilization of adsorbed anion and by the increase of surface coverage.

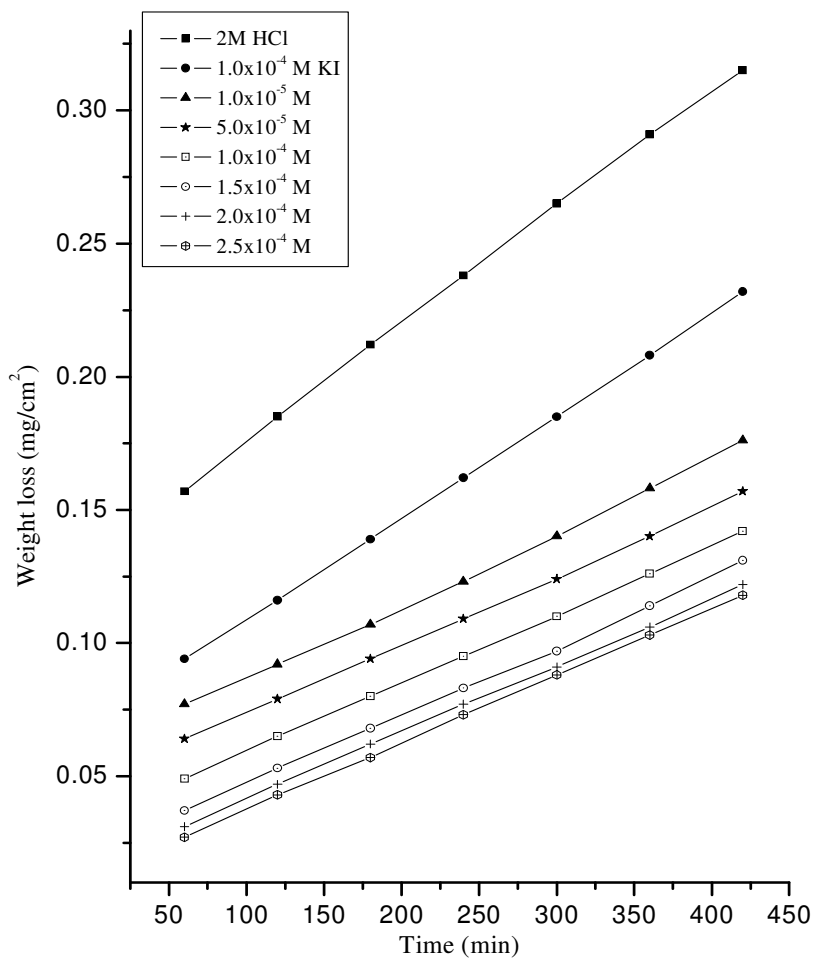

Figure 1. Weight loss-time curves for corrosion of nickel in $2 \mathrm{M} \mathrm{HCl}$ in presence of 1.0 $\times 10^{-4} \mathrm{M} \mathrm{KI}$ and in presence of different concentrations of compound (III) at $30^{\circ} \mathrm{C}$.

Table 2. Variation of percentage inhibition (\%IE) of $\beta$-aminoketones with their concentrations in presence of $1.0 \times 10^{-4} \mathrm{M} \mathrm{KI}$ as calculated from gravimetric measurements after $240 \mathrm{~min}$ immersion at $30{ }^{\circ} \mathrm{C}$.

\begin{tabular}{|c|c|c|c|}
\hline Concentration & \multicolumn{3}{|c|}{ \% Inhibition efficiency } \\
\cline { 2 - 4 }$M$ & I & II & III \\
\hline 0.00 & 31.4 & 31.84 & 31.84 \\
$1.0 \times 10^{-5}$ & 58.63 & 55.21 & 48.24 \\
$5.0 \times 10^{-5}$ & 67.28 & 63.99 & 54.16 \\
$1.0 \times 10^{-4}$ & 71.06 & 69.66 & 60.08 \\
$1.5 \times 10^{-4}$ & 75.39 & 72.18 & 65.13 \\
$2.0 \times 10^{-4}$ & 77.19 & 74.24 & 67.86 \\
$2.5 \times 10^{-4}$ & 79.01 & 76.05 & 69.41 \\
\hline
\end{tabular}


Table 3. Synergism parameter $\left(\mathrm{S}_{\theta}\right)$ calculated from gravimetric technique for different concentrations of $\beta$-aminoketones in presence of $1.0 \times 10^{-4} \mathrm{M} \mathrm{KI}$.

\begin{tabular}{|c|c|c|c|}
\hline Concentration & \multicolumn{3}{|c|}{$\mathrm{S}_{\theta}$} \\
\cline { 2 - 4 } $\mathrm{M}$ & $\mathrm{I}$ & $\mathrm{II}$ & $\mathrm{III}$ \\
\hline $1.0 \times 10^{-5}$ & 1.00 & 0.92 & 0.93 \\
$5.0 \times 10^{-5}$ & 1.09 & 0.99 & 0.97 \\
$1.0 \times 10^{-4}$ & 1.03 & 0.98 & 0.98 \\
$1.5 \times 10^{-4}$ & 1.14 & 1.02 & 0.98 \\
$2.0 \times 10^{-4}$ & 1.12 & 1.05 & 1.04 \\
$2.5 \times 10^{-4}$ & 1.10 & 1.08 & 1.07 \\
\hline
\end{tabular}

\section{Effect of temperature and activation parameters of corrosion process}

The influence of temperature on the corrosion rate in absence and presence of these compounds was investigated by weight loss method. Fig. 2 shows the effect of temperature on the inhibition efficiency (\% IE) of compound III as an example.

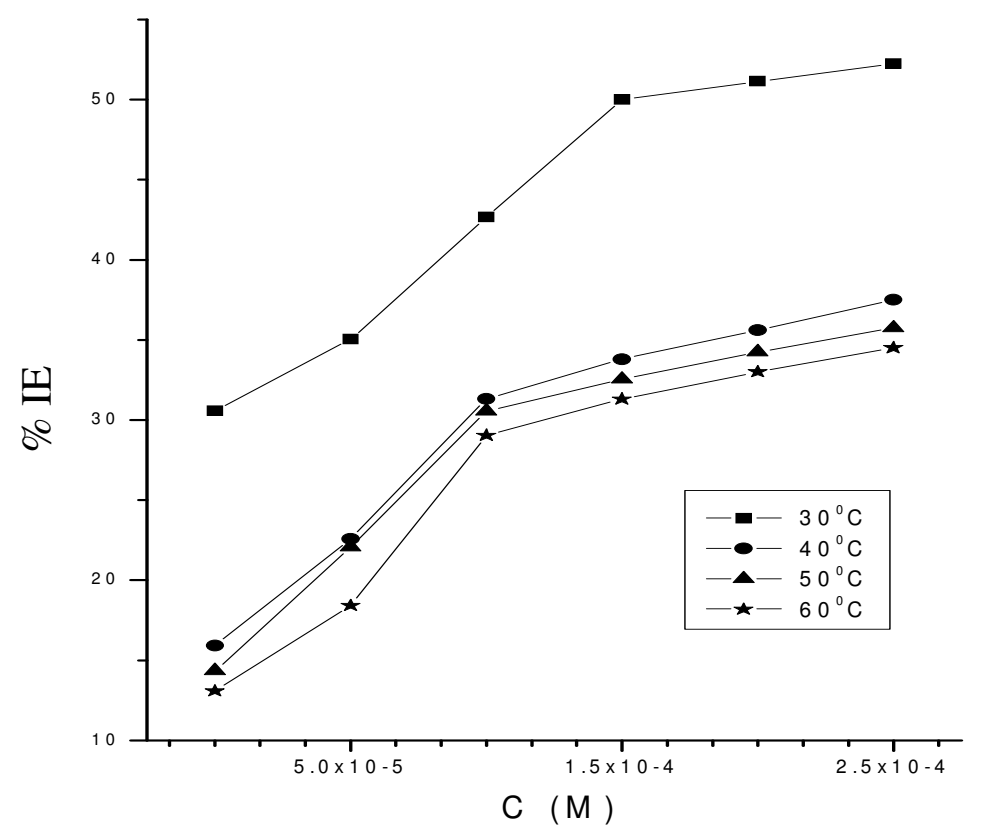

Figure 2. Variation of the inhibition efficiency (\% IE) with the concentrations of compound (III) at different temperatures after $240 \mathrm{~min}$ immersion in $2 \mathrm{M} \mathrm{HCl}$.

It is obvious that the inhibition efficiency decreased with increasing the temperature, indicating physical adsorption of the inhibitor. These curves are of $\mathrm{S}$-shape, i.e. including three portions. The first portion at low inhibitor concentrations along which the \%IE increases gradually due to start formation of monolayer of the inhibitor on nickel surface. At the second portion, the \% IE increases rapidly due to high rate of formation of monolayer of the inhibitor on the nickel surface, so the concentration of the inhibitor in this portion is the best concentration to inhibit nickel corrosion. In the third portion, the adsorbed 
inhibitor molecules saturate the nickel surface and the \%IE acquires a limiting value even by increasing the inhibitor concentration.

Plots of logarithm of corrosion rate $(\log \mathrm{k})$ with the reciprocal of absolute temperature $1 / \mathrm{T}$ for nickel in $2 \mathrm{M} \mathrm{HCl}$ in absence and presence of $1.5 \times 10^{-4} \mathrm{M}$ for all additives are shown in Fig. 3. As shown from their plots, straight lines were obtained with slopes equal to $-\mathrm{E}_{\mathrm{a}}^{*} / \mathrm{RT}$ according to the Arrhenius equation

$$
\log \mathrm{k}=\log \mathrm{A}-\mathrm{E}_{\mathrm{a}}^{*} / \mathrm{RT}
$$

where $\mathrm{k}$ is the corrosion rate $\left(\mathrm{mg} \mathrm{cm}{ }^{-2} \min ^{-1}\right), \mathrm{A}$ is a constant depending on the metal type and electrolyte, $\mathrm{E}_{\mathrm{a}}^{*}$ is the activation energy, $\mathrm{R}$ is the universal gas constant and $\mathrm{T}$ is the absolute temperature. Plots of $\log \mathrm{k} / \mathrm{T}$ vs. 1/T (Fig. 4) give straight lines with slopes of $\left(-\Delta \mathrm{H}^{*} / 2.303 \mathrm{R}\right)$ and intercepts of $[(\log$ $\left.\mathrm{R} / \mathrm{Nh}+\Delta \mathrm{S}^{*} / 2.303 \mathrm{R}\right)$ ] were obtained according to transition state equation

$$
\log k=R T / N h \exp ^{\left(\Delta S^{*} / R\right)} \exp ^{\left(-\Delta H^{*} / R T\right)}
$$

where $\mathrm{h}$ is the Planck's constant, $\mathrm{N}$ is the Avogadro's number, $\Delta \mathrm{H}^{*}$ is the activation enthalpy and $\Delta \mathrm{S}^{*}$ is the activation entropy.

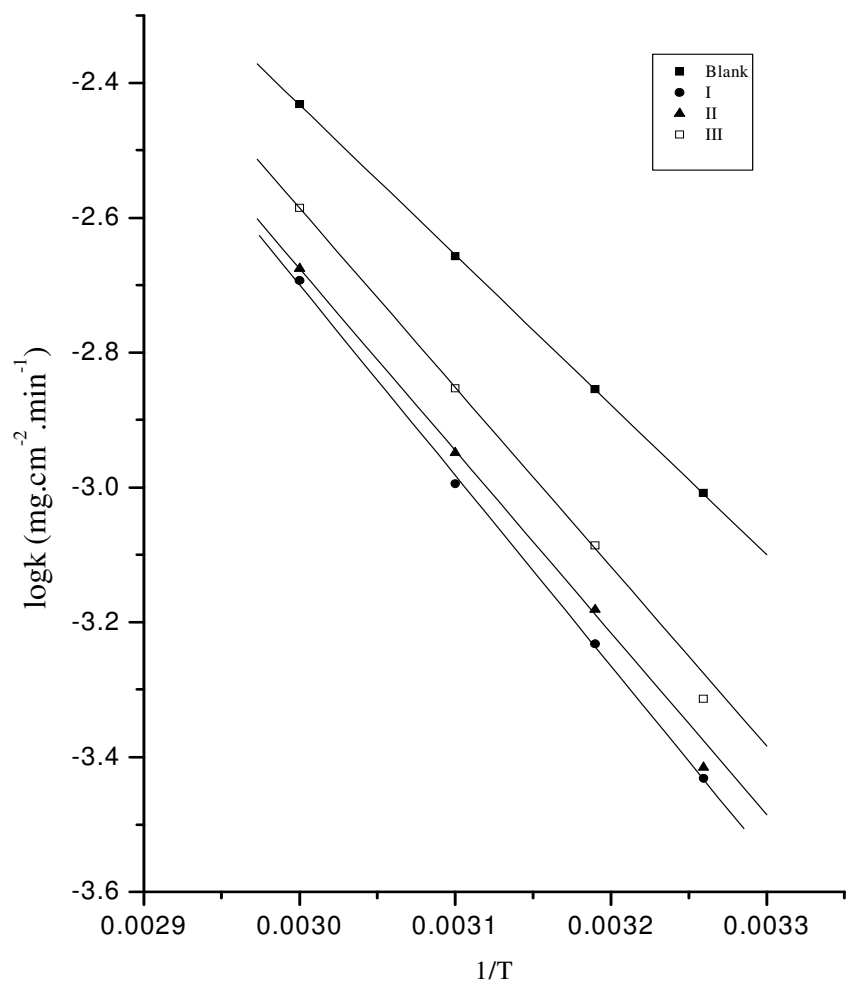

Figure 3. $\log \mathrm{k}-1 / \mathrm{T}$ curves for nickel corrosion in $2 \mathrm{M} \mathrm{HCl}$ in absence and presence of $1.5 \times 10^{-4} \mathrm{M}$ of different compounds.

The calculated values of $\mathrm{E}_{\mathrm{a}}^{*}, \Delta \mathrm{H}^{*}$ and $\Delta \mathrm{S}^{*}$ in absence and presence of $1.5 \times 10^{-4}$ $M$ of the used inhibitors were shown in Table 4 . From these values it can concluded that: 
1) The presence of the inhibitors increases the activation energy of nickel dissolution reaction and the process is activation controlled.

2) The higher value of $\Delta \mathrm{H}^{*}$ in presence of the additives can be explained on the basis that the additives induce the energy barriers for the corrosion reaction. The positive values of $\Delta \mathrm{H}^{*}$ indicate the endothermic nature of corrosion process.

3) The values of $\Delta \mathrm{S}^{*}$ in the presence of the additives are higher than those in their absence and have a negative value. This means that a decrease in disordering takes place on going from reactions to the activated complex [23, 24].

4) From the values of the activation parameters the order of the inhibition efficiencies for the investigated inhibitors is $1>11>111$.

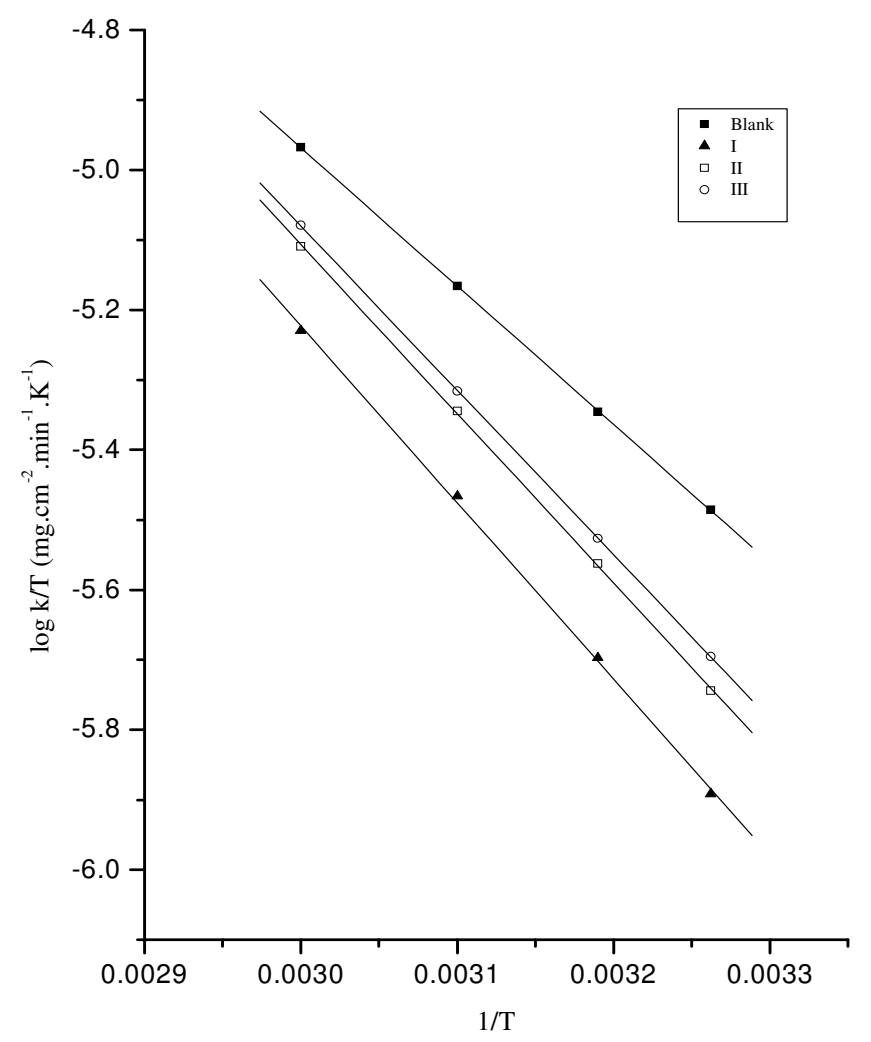

Figure 4. $\log \mathrm{k} / \mathrm{T}-1 / \mathrm{T}$ curves for nickel corrosion in $2 \mathrm{M} \mathrm{HCl}$ in absence and presence of $1.5 \times 10-4 \mathrm{M}$ of different compounds.

Table 4. Values of activation parameters for the dissolution of nickel in the presence of $1.5 \times 10^{-4} \mathrm{M}$ of $\beta$-aminoketones in $2 \mathrm{M} \mathrm{HCl}$.

\begin{tabular}{|c|c|c|c|}
\hline Inhibitor & $\mathrm{E}^{*}, \mathrm{~kJ} \mathrm{~mol}^{-1}$ & $\Delta \mathrm{H}^{*}, \mathrm{~kJ} \mathrm{~mol}^{-1}$ & $-\Delta \mathrm{S}^{*}, \mathrm{~J} \mathrm{~mol}^{-1} \mathrm{~K}^{-1}$ \\
\hline Free acid & 40.69 & 38.06 & 291.66 \\
I & 52.38 & 49.90 & 296.78 \\
II & 50.44 & 48.18 & 296.24 \\
IV & 49.07 & 46.46 & 294.06 \\
\hline
\end{tabular}




\section{Adsorption isotherm}

The degree of surface coverage $(\theta)$ which represents the part of metal surface covered by inhibitor molecules was calculated using equation (2). The degree of surface coverage was found to increase with increasing the concentration of inhibitors. Attempts were made to fit $\theta$ values to various isotherms. The best fit was obtained with Frumkin isotherm according to the following equations [25]:

$$
\begin{gathered}
\theta=\mathrm{A}+(2.303 \mathrm{R} / \mathrm{f}) \log \mathrm{C} \\
\mathrm{f}=1 / \mathrm{RT}\left[\mathrm{d}\left(\Delta \mathrm{G}_{\text {ads }}^{\mathrm{o}} / \mathrm{d} \theta\right]\right.
\end{gathered}
$$

where $\mathrm{A}$ is a constant depending on the nature of the metal and electrolyte, $\mathrm{C}$ is the inhibitor concentration and $\Delta \mathrm{G}_{\text {ads. }}^{\mathrm{o}}$ is the free energy of adsorption. Fig. 5 represents the relation between $\theta$ and $\log \mathrm{C}$ for inhibitor III at different temperatures. The Frumkin adsorption isotherm is obeyed.

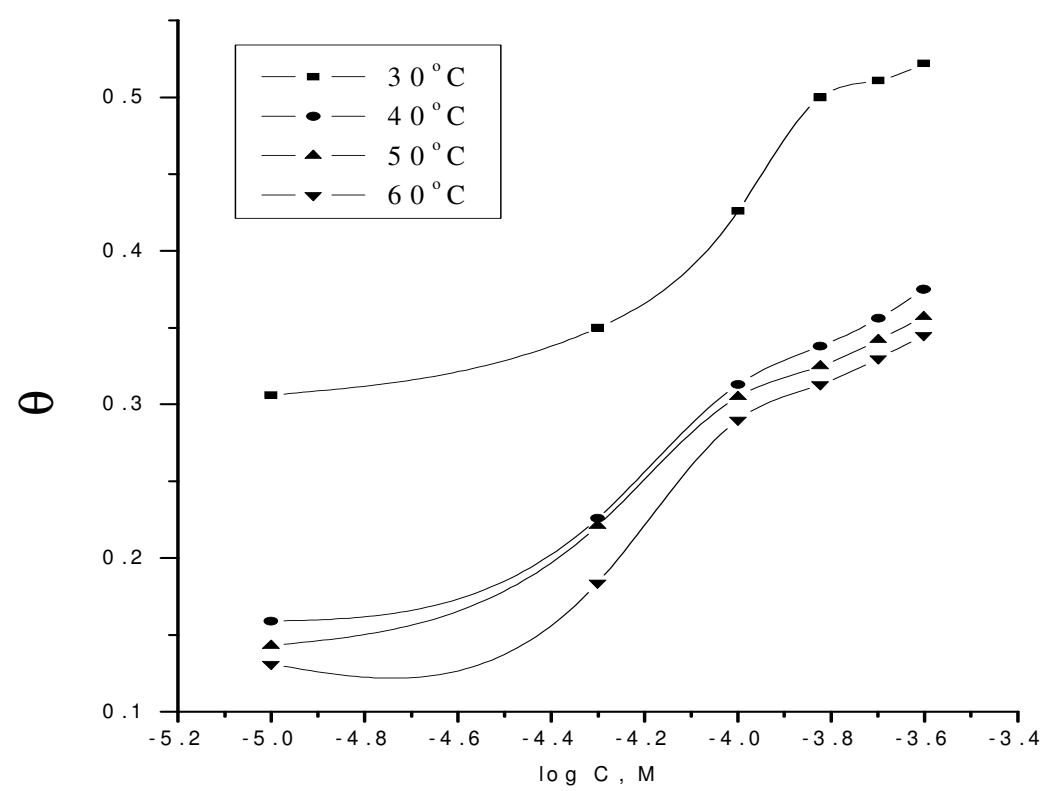

Figure 5. Frumkin's adsorption isotherm for compound (III) at different temperatures from weight loss measurements.

\section{Galvanostatic polarization}

Galvanostatic polarization curves of $\mathrm{Ni}$ specimen in $2 \mathrm{M}$ hydrochloric acid in the absence and presence of different concentrations of the inhibitors at $30{ }^{\circ} \mathrm{C}$ were studied. Fig. 6 shows the behavior of inhibitor I as an example. The numerical values of the variation of corrosion current density $\left(i_{\text {corr. }}\right)$, corrosion potential $\left(E_{\text {corr. }}\right)$, Tafel slopes $\left(\beta_{\mathrm{a}}\right.$ and $\left.\beta_{\mathrm{c}}\right)$, degree of surface coverage $(\theta)$ and inhibition efficiency (\%IE) with the concentrations of compound I are given in Table 5. The following facts were extracted. 
1) Addition of the investigated inhibitors increases both the cathodic and the anodic overvoltage and causes mainly parallel displacement to more negative and positive values, respectively.

2) The corrosion current density ( $\left.i_{\text {corr. }}\right)$ decreases with increasing the concentration of the additives, which indicates that these compounds retard the dissolution of nickel in $2 \mathrm{M} \mathrm{HCl}$.

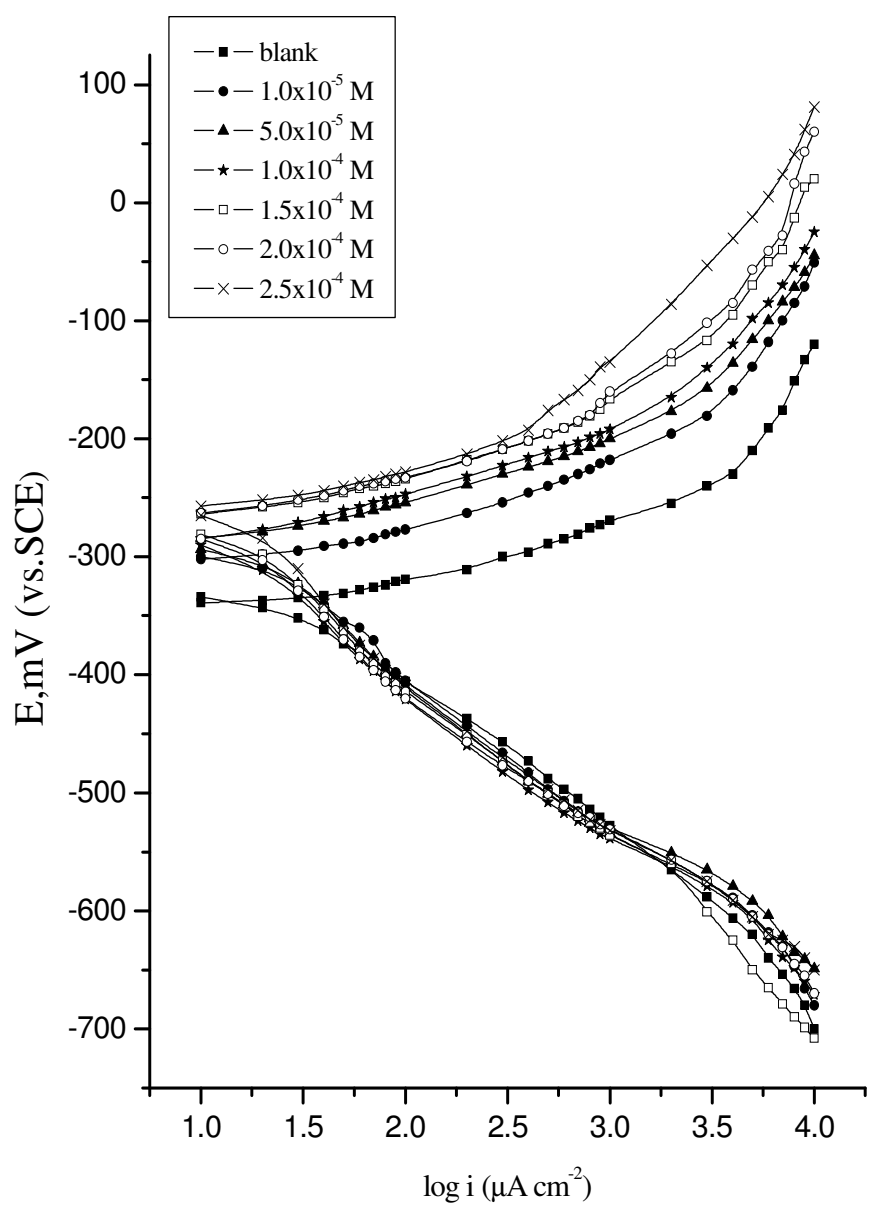

Figure 6. Galvanostatic polarization curves of nickel in $2 \mathrm{M} \mathrm{HCl}$ in presence and absence of different concentrations of compound (I) at $30^{\circ} \mathrm{C}$.

3) The additives influence both cathodic and anodic processes in $\mathrm{HCl}$ solution. This indicates that the additives act as mixed -type inhibitors but the anode is more polarized when external current was applied.

4) The slopes of anodic and cathodic Tafel lines are approximately constant and independent of the inhibitor concentration. This behavior suggests that the presence of inhibitor molecules has no effect on the mechanism of dissolution of $\mathrm{Ni}$.

5) The corrosion potential $\left(\mathrm{E}_{\text {corr. }}\right)$ values shifted to less negative potentials by increasing the concentration of compound I, which confirms that the inhibitors are mainly of the anodic type. 
6) The order of increased inhibition efficiency for the investigated compounds is I $>$ II $>$ III, which agrees with the observed order determined by weight loss method.

Table 5. Data from galvanostatic polarization of nickel in $2 \mathrm{M} \mathrm{HCl}$ containing different concentrations of compound (I) at $30^{\circ} \mathrm{C}$.

\begin{tabular}{|c|c|c|c|c|c|c|}
\hline $\begin{array}{c}\text { Concentration } \\
(\mathrm{M})\end{array}$ & $-\mathrm{E}_{\text {corr. }}(\mathrm{mV})$ & $\begin{array}{c}\mathrm{i}_{\text {corr. }} \\
\left(\mu \mathrm{A} / \mathrm{cm}^{2}\right)\end{array}$ & $\begin{array}{c}\beta_{\mathrm{a}} \\
(\mathrm{mV} / \mathrm{dec})\end{array}$ & $\begin{array}{c}\beta_{\mathrm{c}} \\
(\mathrm{mV} / \mathrm{dec})\end{array}$ & $\theta$ & $\% \mathrm{IE}$ \\
\hline 0.0 & 384.77 & 373.61 & 151.89 & 208.29 & 0.0 & 0.0 \\
$1.0 \times 10^{-5}$ & 336.99 & 218.44 & 138.53 & 195.20 & 0.4153 & 41.53 \\
$5.0 \times 10^{-5}$ & 322.96 & 186.42 & 138.21 & 187.78 & 0.5010 & 50.10 \\
$1.0 \times 10^{-4}$ & 303.02 & 149.79 & 123.43 & 199.48 & 0.5991 & 59.91 \\
$1.5 \times 10^{-4}$ & 249.66 & 137.49 & 134.93 & 225.23 & 0.6320 & 63.20 \\
$2.0 \times 10^{-4}$ & 288.99 & 129.24 & 135.48 & 198.29 & 0.6541 & 65.41 \\
$2.5 \times 10^{-4}$ & 283.58 & 121.26 & 161.26 & 197.78 & 0.6755 & 67.55 \\
\hline
\end{tabular}

Table 6. Quantum chemical parameters for $\beta$-aminoketones.

\begin{tabular}{|c|c|c|c|c|c|c|c|}
\hline Compounds & $\% \mathrm{IE}$ & $\begin{array}{c}\mathrm{i}_{\text {corr. }} \\
\mu \mathrm{A} / \mathrm{cm}^{2}\end{array}$ & $\begin{array}{c}\mathrm{HOMO} \\
\mathrm{eV}\end{array}$ & $\begin{array}{c}\text { LUMO } \\
\text { eV }\end{array}$ & $\begin{array}{l}\text { Dipole moment } \\
(\mu) \text { Debye }\end{array}$ & \multicolumn{2}{|c|}{$\begin{array}{l}\text { Charge } \\
\text { density }\end{array}$} \\
\hline \multirow{3}{*}{ I } & \multirow{3}{*}{67.55} & \multirow{3}{*}{121.26} & \multirow{3}{*}{-12.124} & \multirow{3}{*}{-4.462} & \multirow{3}{*}{8.123} & $\mathrm{~N}$ & 0.647 \\
\hline & & & & & & $\mathrm{O}$ & $\begin{array}{l}-0.275 \\
-0.302\end{array}$ \\
\hline & & & & & & $S$ & $\begin{array}{l}0.405 \\
0.316\end{array}$ \\
\hline \multirow[b]{2}{*}{ II } & \multirow[b]{2}{*}{57.57} & \multirow[b]{2}{*}{158.54} & \multirow[b]{2}{*}{-14.453} & \multirow[b]{2}{*}{-7.715} & \multirow[b]{2}{*}{8.121} & $\mathrm{~N}$ & $\begin{array}{l}0.615 \\
0.508\end{array}$ \\
\hline & & & & & & $\mathrm{O}$ & $\begin{array}{l}-4.408 \\
-0.415\end{array}$ \\
\hline \multirow[b]{2}{*}{ III } & \multirow[b]{2}{*}{54.02} & \multirow[b]{2}{*}{171.80} & \multirow[b]{2}{*}{-12.374} & \multirow[b]{2}{*}{-4.447} & \multirow[b]{2}{*}{7.282} & $\mathrm{~N}$ & 0.645 \\
\hline & & & & & & $\mathrm{O}$ & $\begin{array}{l}-0.285 \\
-0.297\end{array}$ \\
\hline
\end{tabular}

Values of $\mathrm{i}_{\text {corr. }}$ were calculated in presence of $2.5 \times 10^{-5} \mathrm{M}$ inhibitor.

Correlations between inhibition actions, chemical structure and quantum chemical calculations of the inhibitor

The quantum chemical data including charge densities on the $\mathrm{N}, \mathrm{S}$ and $\mathrm{O}$ atoms are summarized in Table 6 . The prospective structure of the inhibitors as obtained from geometry optimization is shown in Fig. 7. Adsorption of inhibitors involves charge sharing or charge transfer from the inhibitor molecules to the metal surface to form a coordinate-type bond. It corresponds to a planer 
orientation of the molecule on the metal surface through $\pi$-electron of the benzene or thiophene rings in the molecule. Other sites may enhance the adsorption capability of these $\beta$-aminoketone molecules. This could be due to the electrostatic attraction between $\mathrm{N}, \mathrm{O}$ and/or $\mathrm{S}$ atoms and the negative sites induced on the metal surface $[26,27]$. The molecular orbital calculation indicates that $\mathrm{O}$ atoms of the $\mathrm{C}=\mathrm{O}$ groups acquired a negative charge which makes it easy to react with the strong acidic medium $(2 \mathrm{M} \mathrm{HCl})$ rather than with the metal surface. When inhibited solutions contain absorbed anions, such as $\mathrm{Cl}^{-}$ions, these adsorb on the metal surface creating dipoles. Consequently, this results in an increase in the adsorption, and in the capability of the cationic inhibitor. In this case, a positive synergistic effect arises [28, 29].

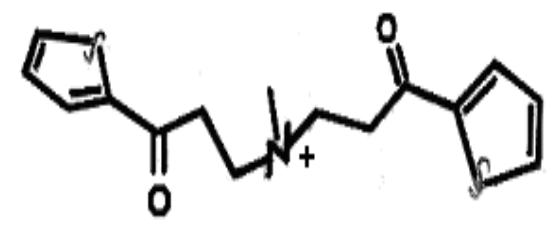

Inhibitor I

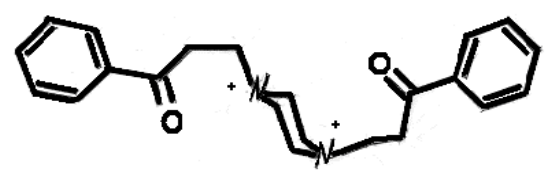

Inhibitor II

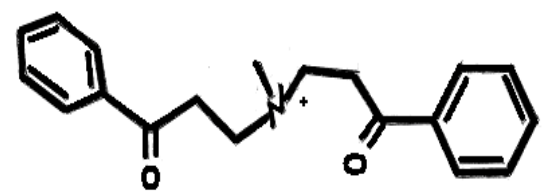

Inhibitor III

Figure 7. Geometry of the inhibitors.

For compounds I and III, the results obtained from the relation between inhibition characteristics and quantum chemical data show that $\mathrm{i}_{\text {corr. }}$ mostly depends upon the energies of the highest occupied molecular orbital (HOMO) (see table 6), while the lowest unoccupied molecular orbital (LUMO) didn't change markedly. For compound II, the presence of the piperazine ring (not present in compounds I and III) causes a general increase in the energy of their molecular orbitals including HOMO and LUMO. It is further evident that the inhibition efficiency increases with the ease of ionization of the molecule, which means that the molecule acts as an electron donar when blocking the corrosion reaction.

The calculated values of the total molecular dipole moments show a general increase of the corrosion rate with decreasing the dipole moment of the inhibitor, 
thus the lower rate of corrosion current corresponding to the highest value of dipole moment.

Generally, the results of weight loss, galvanostatic polarization, synergistic studies and the MO calculation revealed that the order of inhibition of $\beta$ aminoketone is as follows: I > II > III.

\section{Conclusion}

$\beta$-aminoketones inhibit nickel corrosion in hydrochloric acid solution. The inhibitor molecules are adsorbed on the metal surface following Frumkin adsorption isotherm and inhibit the corrosion rate better than the passive oxide film. The efficiency of the inhibitors increases in the presence of iodide ions as a result of synergistic effect. Galvanostatic measurements indicate that the inhibitors act as a mixed-type but the anode was more polarized. The order of inhibition efficiency of the inhibitors is the same in case of gravimetric, galvanostatic and quantum chemical calculations. This confirms the results obtained from the three different techniques.

\section{References}

1. J.R. Kish, M.B. Ives, J.R. Kodda, J. Electrochem. Soc. 144 (2000) 3637.

2. M. Keddam, H. Takenouti, N. Yu, J. Electrochem. Soc. 132 (1985) 2561.

3. T. Ohisuka, K.E. Heusler, J. Electroanal. Chem. 102 (1979) 175.

4. N. Sato, K. Kudo, Electrochim. Acta 19 (1974) 461.

5. G. Gilli, P. Borea, F. Zuccki, G. Trabanelli, Corros. Sci. 13 (1973) 1585.

6. E. Khamis, F. Bellucci, R.M. Latanision, E.S.H. El-Ashry, Corrosion 47 (1991) 677.

7. E.E. Abdelaal, W. Zakria, A. Diab, S.M. Abdel Haleem, J. Chem. Tech. Biotech. 74 (1999) 1061.

8. $\quad$ K. Bajpai, G. Singh, Bull. Electrochem. India 16 (2000) 241.

9. A.S. Fouda, A.A. El-Shafie, H.S. Gadow, Electrochim. Acta 20 (2002) 13.

10. E.E. Abdelaal, Corros. Sci. 45 (2003) 759.

11. M.R. Laamari, A. Derja, J. Benzakour, M. Berraho, J. Electroanal. Chem. 1 (2004) 56.

12. S.M. Rashwn, A. Emam, S.M.A. El-wahab, M.M. Mohamed, J. Mater. Sci. Technol. 20 (2004) 121.

13. A.G. Munoz, M.E. Vela, Corros. Sci. 47 (2005) 2293.

14. F. Said, N. Souissi, K.E.S. Salah, N. Hajjaji, E. Triki, A. Srhire, J. Mater. Sci. 42 (2007) 4040.

15. F.F. Blicke, J.H. Burckhalter, J. Am. Chem. Soc. 64 (1942) 451.

16. C. Mannich, D. Lammering, J. Ber. 55B (1922) 3510.

17. L. Natova, D. Mondeshka, L. Zhelyazkov, God. Vissh., Khim.- Technol. Inst. Sofia 24 (1978) 47.

18. E.D. Taylor, W.L. Nobles, J. Am. Pharm. Assoc. Sci. Ed. 49 (1960) 317.

19. N. Hackerman, E.S. Jr. Snavely, J.S. Jr. Payne, J. Electrochem. Soc. 113 (1966) 677.

20. N. Cahskan, S. Bilgic, J. Appl. Surf. Sci. 153 (2000) 128. 
21. G. Schmite, K. Bedbur, Werkst. U. Korros. 361 (1985) 273.

22. K. Aramaki, N. Hackerman, J. Electrochem. Soc. 116 (1969) 568.

23. M.K. Gomaa, M.H. Wahdan, Mater. Chem. Phys. 39 (1995) 209.

24. J. Marsh, Advanced Organic Chemistry, $3^{\text {rd }}$ ed., Willey Eastern, New Delhi (1998).

25. D.W. Atkins, "Physical Chemistry", Oxford University Press, Oxford, $5^{\text {th }}$ ed., p. 992 (1994).

26. N. Hajjaji, I. Rico, A. Srhiri, A. Latteo, M. Soursiaui, A. Ben Bachir, Corrosion 49 (1993) 326.

27. M. Elachowi, M.S. Hajji, S. Kertit, E.M. Essassi, M. Salem, R. Coudert, Corros. Sci. 37 (1995) 381.

28. G. Banerjee, S.N. Malhorta, Corrosion 48 (1992) 10.

29. D.P. Schweinsberg, V. Ashworth, Corros. Sci. 28 (1988) 539. 